\title{
Research on the Hanfu Movement in New Media Environment
}

\author{
Huansong Yang ${ }^{1}$, Weiran Dou ${ }^{2}$, Zhifei Chen ${ }^{3 *}$
}

\author{
${ }^{1}$ Hangzhou Normal University \\ ${ }^{2}$ Hangzhou Normal University \\ ${ }^{3}$ Hangzhou Normal University \\ *Corresponding author. Email: chen_zzhifei@163.com
}

\begin{abstract}
Secretary-General Xi Jinping has put forward the requirement of "double creation" for the excellent Chinese traditional culture, which is of great significance for the inheritance and development of traditional culture. Through the new media, the Hanfu movement has been able to gain momentum, and through this channel, the public can better understand the historical background of Hanfu, its development status and its necessity. By studying the development of Hanfu in the new media, we can understand the difficulties encountered by the Hanfu movement at this stage, point out the advantages and disadvantages of the new media in the promotion of Hanfu at this stage, and analyse and propose relevant solutions to overcome the bottlenecks encountered by the Hanfu movement, so as to promote Hanfu to the greatest extent possible and contribute to a strong cultural nation.
\end{abstract}

Keywords: Hanfu Movement, New Media, Traditional Culture, Promotion Innovation

\section{THE DEVELOPMENT AND SIGNIFICANCE OF THE HANFU MOVEMENT IN THE NEW MEDIA ENVIRONMENT}

The Hanfu movement is a folk activity in which supporters and revivalists of traditional culture, regardless of age, gender, status and hobbies, use the revival of traditional Han Chinese costumes as an entry point to influence the public and thus promote the essence of excellent Chinese culture. The Hanfu movement is one of the means to revitalize the essence of Chinese culture at this stage, and one of the forms of the Chinese national revival movement.

At present, the spread and development of the Hanfu movement is still mainly based on some social software that was born out of new media technology, such as Baidu Post Bar and Weibo. However, in recent years, with the opening of many Hanfu stores in major cities, as well as the rise of cultural and art organizations and commercial service establishments related to traditional culture, the Hanfu movement has gradually begun to move closer from being a hot topic on the Internet to the public's daily life.
From 2017 to 2019, the number of Hanfu cultural associations worldwide increased from more than 1,300 to more than 2,000. According to media reports, in 2019, the number of consumers in the national Hanfu market has exceeded 2 million, and the total scale of the Hanfu industry is about 1.09 billion yuan. This shows that Hanfu has long since metamorphosed from a niche cultural circle into the public eye and has contributed to the generation of a whole new industrial chain.

In view of the confusion between the concepts of Hanfu and ancient costumes, and in order to better enumerate the author's views later on, I would like to give a conceptual analysis of the two to reflect their differences. Hanfu refers to the traditional clothing and accessory system that is clearly distinguished from other ethnic groups from the reign of the Yellow Emperor to the middle of the 17th century A.D., with the background and dominant idea of "Huaxia-Han" culture and the Chinese ritual culture as the center; while ancient costumes, in the perception of Hanfu circles, mostly refer to the traditional clothing and accessory system made of very incorrect forms and imitations. In Hanfu circles, ancient costume refers to clothing that is very incorrect and imitates Hanfu, which is mostly found in movies and TV dramas. 


\section{PROBLEMS OF THE HANFU MOVEMENT IN THE NEW MEDIA ENVIRONMENT}

The Hanfu movement has been developing for 18 years since it started in 2002. From online to offline, the Hanfu movement has continued to enrich its connotation and deepen its research, and as the number of Hanfu movement participants has increased and the influence of the crowd has grown, it has gradually formed a complete industrial chain. The Hanfu movement has been created and further expanded through new media, but the new media environment has also exposed many problems.

\subsection{Worship of Face Value}

With the development of new media technology, the phenomenon of "face reverence" has become more evident in modern society. Richard Shusterman explicitly introduced the concept of human aesthetics, he discussed the importance of human aesthetics in the aesthetic experience. Body beauty has become a new consumer product, and in the current social evaluation index system, the weight of "appearance" is increasing, and young people's preference for "appearance" has become a fashion trend. [1]

In the new media consumer society, the body has broken through the confines of the physical body and has taken on a symbolic meaning. While promoting itself, the Hanfu movement has inevitably fallen into the dilemma of focusing too much on the external appearance and neglecting the internal value of the Hanfu movement. In the selection of today's Hanfu competitions in colleges and universities, the public also tends to prioritize ordinary people with high facial values over ordinary people with average but more talented faces, leading to the superficiality of Hanfu communication. In the production of Hanfu, many Hanfu vendors focus too much on the beauty of the pictures to the neglect of the shape and quality of the clothes, which leads to many new Hanfu participants becoming disillusioned with the Hanfu world and opting out.

\subsection{Commercialization Drawbacks}

The Hanfu movement has been developing for 18 years since it started in 2002. From online to offline, the Hanfu movement has continued to enrich its connotation and deepen its research, and as the number of Hanfu movement participants has increased and the influence of the crowd has grown, it has gradually formed a complete industrial chain. The Hanfu movement has been created and further expanded through new media, but the new media environment has also exposed many problems.

Secretary-General $\mathrm{Xi}$ Jinping has repeatedly emphasized the importance of a strong cultural nation, while China's cultural industry has a large gap compared to developed countries and has not yet been transformed into a pillar industry of the national economy. In view of this, many competitions have been held jointly by local ministries of culture and universities to promote traditional Chinese culture, and the Hanfu competition is one of the important competitions, which has indeed played a great role in promoting the spread of Hanfu culture, but many problems have been revealed during the competition: the lack of professionalism of judges, participants mistaking ancient costumes/Chinese elements for Hanfu, etc.

The phenomenon of Chinese costume spreading deviating from the original intention is not only offline, but also exists in large numbers online. When you search for the keyword Chinese costume on the bilibili platform, the top two videos are with 11.1 million views are Sending the Bright Moon Flip Jump and Drumming the King of Laning's Entry Song with 7.85 million plays. These people who take ancient costumes as hanfu are undoubtedly using hanfu as a gimmick to gain benefits, and this phenomenon is also the result of various capital games. After the expansion of the hanfu circle, many companies that know little about hanfu also want share the benefits, which is why the phenomenon of incestuous Hanfu has emerged. With the expansion of the Hanfu industry, some Hanfu merchants no longer invest in the pattern and quality of Hanfu in order to make profits, and sell Hanfu with mismatched money and goods, inflated prices, and poor service attitude of merchants. But if these drawbacks further deteriorate into serious ills, the Hanfu circle will suffer a really serious blow when the Hanfuloving consumers become discouraged.

\section{PROMOTION AND INNOVATION OF HANFU MOVEMENT IN NEW MEDIA ENVIRONMENT}

Obviously, advocates and participants of the current Hanfu movement need to stay awake enough behind the flashy appearance, stick to the self-confidence and originality of Hanfu culture, and use the power of new media to cooperate with other excellent traditional cultures and excellent means of communication in "both form and spirit". At the same time, we give full play to our natural advantages based on original and original IP, tap into the existing story resources, and improve our market competitiveness in the cultural industry, so as to achieve the promotion and innovation of Hanfu culture altogether. [2]

\subsection{Building IP}

At present, the IP industry chain in China is still not mature enough, so cultural enterprises and institutions are paying much attention to the creation of IP. For example, Tang Niu, the image spokesperson of Shanxi History Museum, is its own original IP, which originates from the 
Tricolor-glazed Pottery figure of court ladies of the Tang Dynasty in Shanxi History Museum, and through Tang Niu, Shanxi History Museum tells the story of Tang Dynasty and conveys the culture of Tang Dynasty, which attracts a lot of fans and visitors to the museum. Mr. Er Qiao, the author of Tang Niu Arrives, was the guest of honour on the same stage with Taobao anchor Viya, and the sales were as high as 20,000 copies within 3 seconds.

This shows how necessary it is for the cultural industry to create IP to promote the industry. Therefore, Hanfu promoters can also actively promote cooperation with illustrators to create interesting Hanfu IP images, which can be used as a fulcrum to better promote Hanfu culture.

\subsection{Brand Collaboration}

Along with the rapid development of new media, brand communication presents a trend of combining youth subculture. Relying on youth subculture on the Internet, brand communication can successfully aggregate target audiences, realize brand personalization and style niche, and generate huge economic benefits. [3]

Take Alpha Group Co., Ltd. as an example, Alpha Group Co., Ltd. and Netease's classic IP mobile game Yin Yang Shi co-branded, launched a series of Yin Yang Shi mystery boxes, synchronized in the Miniso, Tmall and other channels to store, as of September 30, 2020, the series of mystery boxes accumulated sales of more than 446,000 .

Take UNIQLO for example, UNIQLO's brand positioning is inexpensive and good quality, adhering to the business philosophy of providing consumers with "low-priced good products, quality assurance", has been widely loved by consumers. Although Uniqlo mainly focuses on basic casual wear, it also pays great attention to the role of youth subculture in promoting apparel, which is mainly reflected in UNIQLO's occasional cooperation with various IPs to launch various types of basic clothes with personalized styles, such as the launch of the "original nostalgic UT series to celebrate the 50th anniversary of Doraemon in 2020 For example, in 2020, we will launch the "Original nostalgic UT series to celebrate the 50th anniversary of Doraemon", the "LOL SURPRISE" co-branded doll and the co-branded clothes with Disney's "Mickey Aloha", etc. By borrowing and incorporating the subcultural symbols loved by youth, those collaboration clothing are able to go well beyond the conventional casual clothes, they have achieved a niche style that continues to attract young consumers and form a group of loyal fans.

\subsection{Cultural Fusion}

Take the award-winning digital media work Yun Xiang Yi Shang as an example, although it is a Hanfu- themed work, its creation is not limited to the aspect of clothing, but also actively incorporates elements of other traditional cultures. For example, the ink and wash style is the main tone, the unfolding scroll is used as the text background, the pure sound of ancient style played by ocarina, pipa and guzheng is used as the background music, and the original ancient style dance is integrated into the background of Chinese painting. It can be seen that the benefits of integrating other traditional cultures and new media technology to promote Hanfu culture, other traditional cultures, new media technology, and Hanfu culture are a mutually reinforcing partnership. People can better promote and revitalize Hanfu culture by carrying out specific cultural activities practice with Hanfu as the carrier, and also increase the depth and breadth of Hanfu culture, meanwhile people can learn ancient etiquette and appreciate the fun of Hanfu culture in the Hanfu culture.

\subsection{Stick To The Network Front To Help Promote Hanfu Culture}

The popularity of Hanfu is inseparable from the persistent promotion of Hanfu culture enthusiasts. The popularity of Hanfu culture originated at the beginning of this century, when netizens took forums and Baidu posting bars as their positions, and at first only some Hanfu enthusiasts exchanged ideas through forums and held activities offline to draw people's attention to Hanfu culture by wearing Hanfu to worship national heroes and holding ceremonial activities. However, after 2010, with the opening of the Hanfu bar on Baidu, netizens who love Hanfu culture began to put down roots in the Hanfu bar, although the growth rate of bar users was not fast. From the decade of 2011 to 2021, the number of Hanfu bar users grew at an average size of about 100,000 a year. As of today, the Hanfu bar has close to 1.2 million followers and nearly 15 million cumulative posts. These Hanfu enthusiasts have not only established a small circle online, but also founded the China Hanfu Culture Promotion Association in 2013. Perhaps it is the persistence of these Hanfu enthusiasts and their continuous promotion of Hanfu culture that has finally led to a quantitative change and a huge Hanfu movement.

With the rise of the short video platform, Hanfu enthusiasts have another place to find fellowship. When you search for Hanfu on Douyin, the total number of videos on related topics has exceeded 48.5 billion, due to the inclusive nature of Douyin, where "ordinary users who consistently produce quality video content have many opportunities to grow into social stars," the hanbok movement "is created and perpetuated in a continuous, dynamic, highly interactive process." [4] Not only that, but on other social media platforms such as Weibo and Zhihu, netizens are also enthusiastically discussing and communicating Hanfu culture. Searching Hanfu on Weibo, Hanfu not only has a fan base of nearly 1.8 million 
followers official account Weibo Hanfu, but also an exclusive Hanfu Weibo's Chaohua (super topics), with more than 3.4 billion reads and nearly 500,000 fans, and nearly 110,000 discussion posts with many netizens sharing Hanfu photos and discussing Hanfu-related topics. There is also no shortage of professional discussions about hanbok on the text-based Zhihu. What is clear is that Hanfu culture has become a cultural trend on all major social media platforms. From forums, to postings, to Jitterbug, the transformation of social media has contributed to the metamorphosis of Hanfu culture from a niche to a popular circle.

\subsection{Promotion and Innovation of E-Commerce Platform}

With the rise and rapid development of shopping platforms such as Taobao, Vipshop and Tmall, online shopping is more convenient and stimulates more interest in buying compared to physical stores. This means that Hanfu consumers can not only enjoy the services of a physical store, but can also pick and choose from different kinds of Hanfu online. For stores that sell Hanfu, they need to attract more potential target groups by being innovative in design, promoting Hanfu with the e-commerce platform itself, and supplementing it with media such as Weibo and Douyin to impress the audience with the products, the Hanfu culture and even the store owners. And keep improving the Hanfu and its accessories around, because some of them have the problem of inconvenience while wearing them, and it is believed that after the emergence of designs that balance aesthetics and practicality, Hanfu will get a new vitality.

\section{CONCLUSION}

As one of the countries with the longest history in the world, China has a glorious culture, but it has also experienced traumatic experiences such as the Opium War and the War of Resistance against Japanese Aggression, and contemporary China inevitably faces social problems such as urbanization and aging. As one of the traditional Chinese national costumes, Hanfu deserves to be inherited and innovated. As the original intention of the Hanfu movement says, "It starts with the clothes and crowns, and reaches to the far end" [5], the Hanfu movement is not a comprehensive retro copy, but a movement that hopes to draw the attention of the society to the Hanfu and make the society as a whole pay more attention to the essence of the traditional culture, so as to find a modernization path that suits China's national conditions, and at the same time remove the dregs, dispel some bad customs in society, and improve the country's cultural soft power.

The revival of costume culture reflects the rise of Chinese culture and the cultural confidence of contemporary Chinese people. In the context of globalization and in the face of strong pressure from Western culture, the use of Chinese costumes to highlight the unique charm of Chinese culture is an important means of enhancing our cultural soft power.

\section{ACKNOWLEDGMENTS}

This research is supported by the Hangzhou Normal University Digital Cultural and Creative Industry Integration Between Industry and Education Project from the list of Zhejiang Province 2019-2020 Provincial Integration Between Industry and Education Project.

\section{REFERENCES}

[1] Yaqin Wang, The Phenomenon of Face Reverence in Film and Television from the Perspective of Body Aesthetics, in: Movie Literature, vol. 16, 2017, pp. 7-9. DOI: https://doi.org/10.3969/j.issn.04955692.2017.16.003.

[2] Lulu Cai, Analysis of Chinese Hanfu Culture Communication Strategy in the Context of New Media, in: Journalism Research Herald, vol.10, 2019, pp. 21-22. DOI https://doi.org/10.3969/j.issn.16748883.2019.10.012

[3] Wang Rui, Chen Yuqing, Fu Guanming, The Development of Hanfu Culture in the New Era, in: Chinese and Foreign Entrepreneurs, 2019, pp. 148

[4] Mei Na, Xiaojuan Chen, A Study on the Mode of Dissemination of Non-Foreign Heritage by "Douyin" Short Video, in: Press Utpost, vol.5, 2019, pp. 28-29. DOI: https://doi.org/10.3969/j.issn.10032827.2019.05.014

[5] Dong Meng, Research on the Communication Characteristics of Hanfu Culture in the New Media Era, in: Sinogram Culture, 2021, pp. 159-160. DOI: https://doi.org/10.14014/j.cnki.cn112597/g2.2021.04.074 